\title{
MISLEADING SHADOW
}

\author{
Sreenivas Gouripeddi ${ }^{1}$, Chandrasekhar Veccham ${ }^{2}$
}

\section{HOW TO CITE THIS ARTICLE:}

Sreenivas Gouripeddi, Chandrasekhar Veccham. "Misleading Shadow". Journal of Evolution of Medical and Dental Sciences 2015; Vol. 4, Issue 52, June 29; Page: 9134-9136, D0I: 10.14260/jemds/2015/1326

\begin{abstract}
In a suspected foreign body of bronchus or esophagus a radiograph of chest is essential and sometimes artifacts on radiographs mislead the treating doctor. A round radio opaque shadow on a radiograph of chest in a child who was operated for atrial septal defect mislead for a coin in esophagus and knowledge of the shadow avoided major surgical intervention.
\end{abstract}

KEYWORDS: Foreign body, Artifact, Radiograph.

INTRODUCTION: In suspected foreign body throat or bronchus, x-ray chest AP view is the initial investigation performed and the shadows over the radiographs may sometimes mislead the treating doctor.[1] In these cases proper care should be exercised in diagnosing and treating a suspected foreign body, particularly in children who may not give proper history of ingestion or aspiration of foreign body. In such cases, proper history from the parents sometimes may avoid major surgical intervention. Here, we are presenting a case with suspected foreign body in esophagus in a child in whom history revealed cardiac surgery for atrial septal defect which was later proved to be the cause for 'misleading shadow'.

CASE REPORT: A 10 year old female child was referred to ENT OPD, SVRRGGH, Tirupati, AP by a Pediatrician with a suspected foreign body esophagus of one week duration. The parents were apprehensive and on examination the child was healthy, able to swallow liquids and solids freely without any symptoms of foreign body impaction. Parents revealed that X-ray chest was taken on the advice of pediatrician as the child had cough for the past 3 days and he suspected foreign body impaction as the radiograph was showing a round radiopaque shadow in the middle of the chest (Fig. 1). Further, parents gave a history that the child underwent a major cardiac surgery 3 years back. We repeated the x-ray chest AP view which showed the same radio opaque shadow in the same position (Fig. 2). The records pertaining to the patient's history showed that the child underwent a surgery for atrial septal defect and ASD device was used to close the defect. Thus the shadow on radiograph was confirmed as ASD device which mislead the treating doctor. The child was sent home with the reassurance given to the parents regarding the shadow on radiograph.

DISCUSSION: Artifacts commonly seen in chest radiographs mislead the treating doctor. The familiarity and knowledge of various surgical materials used in various cardiac surgeries can help clinicians in differentiating these from the artifacts.[1] Adequate knowledge of the types of various surgical materials which produce shadows on radiographs and cautious reading of radiographs may prevent unnecessary interventions. The knowledge of some common radio opaque structures which may appear as artifacts and which may mislead should be kept in mind. The surgical material like vascular clips, stents, sternal wires, needles, intra-aortic balloon catheter tips, ASD devices and so on produce shadows on radiographs.[1,2] Sometimes in off-pump coronary artery bypass radiographs, the ring shadows mislead the treating doctors alike.[3] In one patient as reported by Arora and others the hearing aid of a patient appeared as pacemaker of heart on chest radiograph. ${ }^{[4]}$ 
These abnormal shadows may sometimes mislead and have medico legal consequences. Discussion with the radiologist is helpful not only in making correct diagnosis of the artifacts or shadows on radiographs but also avoid unnecessary investigations. ${ }^{[5]}$ Proper verification of records, detailed history regarding previous surgeries specifically cardiac and discussion with the radiologist not only make proper diagnosis but also avoid major investigations and interventions.

\section{REFERENCES:}

1. Tim B. Hunter, Mihra S. Taljanovic, Pei H. Tsau, William G. Berger, James R. Standen. Medical devices of the Chest. Radiographics. 2004; 24: 1725-46.

2. Wolfson KA, Seeger LL, Kadell MB, Eckardt JJ. Imaging of surgical paraphernalia: What belongs in the patient and what does not. Radiographics. 2000; 20: 1665-73.

3. Chakravarthy M, Patil TG, Jawali V, Jayaprakash K, Shivananda N. Radio-opaque foreign body on a postoperative chest X-ray. J Cardiothorac Vasc Anesth. 2004; 18: 673-4.

4. Arora D, Mehta Y. An unidentified object in the chest? J Cardiothorac Vasc Anesth. 2008; 22: 930-1.

5. Narayan P, Das D and Das M. Artifact on postoperative chest radiograph, mimicking retained foreign body. Asian Cardiovascular \& Thoracic Annals 2015; 23(1): 85.

Fig. 1: X-Ray Chest A-P view. Arrow pointing a round radio opacity.

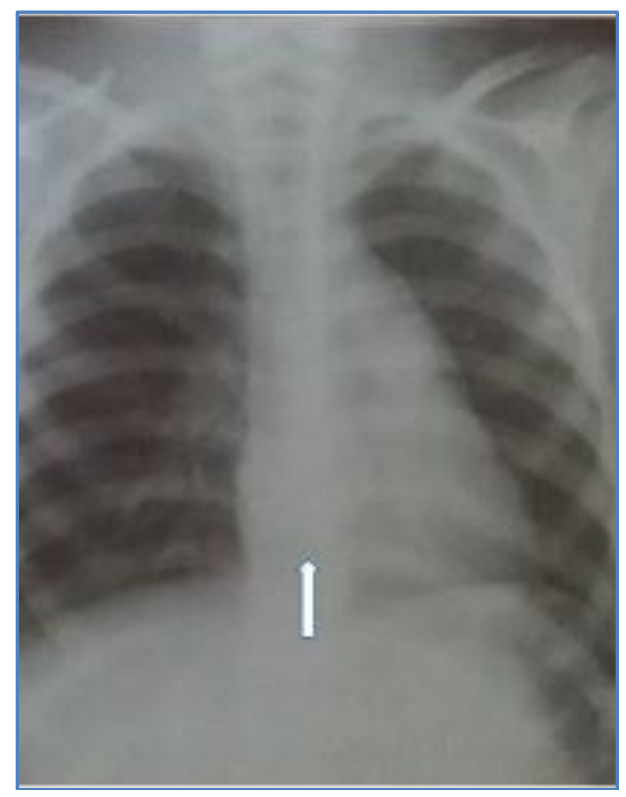

Fig. 1 


\section{CASE REPORT}

Fig. 2: X-ray Chest Including abdomen A-P view. Arrow pointing round opacity at same site.

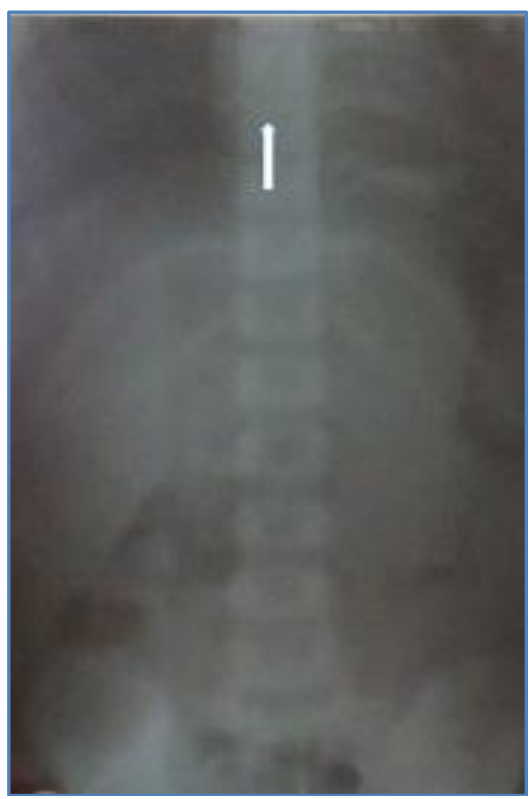

Fig. 2

\section{AUTHORS:}

1. Sreenivas Gouripeddi

2. Chandrasekhar Veccham

\section{PARTICULARS OF CONTRIBUTORS:}

1. Assistant Professor, Department of ENT, SVMC/SVRRGGH, Tirupati, Andhra Pradesh.

2. Associate Professor, Department of ENT, SVMC/SVRRGGH, Tirupati, Andhra Pradesh.

\section{FINANCIAL OR OTHER}

COMPETING INTERESTS: None
NAME ADDRESS EMAIL ID OF THE CORRESPONDING AUTHOR:

Sreenivas Gouripeddi, Assistant Professor, Department of ENT, SVMC/SVRRGGH,

Tirupati-517507,

Andhra Pradesh, India.

E-mail: vas_gouripeddi@yahoo.co.in

Date of Submission: 05/06/2015.

Date of Peer Review: 06/06/2015.

Date of Acceptance: 20/06/2015.

Date of Publishing: 29/06/2015. 